\title{
Francis MESSNER (dir.), L'affiliation religieuse en Europe
}

Strasbourg, Presses universitaires de Strasbourg, 2017

\section{Philippe Ségur}

\section{(2) OpenEdition}

\section{Journals}

Édition électronique

URL : http://journals.openedition.org/rdr/369

DOI : $10.4000 /$ rdr.369

ISSN : 2534-7462

Éditeur

Presses universitaires de Strasbourg

\section{Édition imprimée}

Date de publication : 6 novembre 2018

Pagination : 188-189

ISBN : 979-10-344-0023-2

ISSN : 2493-8637

Référence électronique

Philippe Ségur, « Francis messner (dir.), L'affiliation religieuse en Europe », Revue du droit des religions [En ligne], 6 | 2018, mis en ligne le 25 novembre 2019, consulté le 20 novembre 2020. URL : http:// journals.openedition.org/rdr/369; DOI : https://doi.org/10.4000/rdr.369

Ce document a été généré automatiquement le 20 novembre 2020.

\section{(c) (1) (5)}

La revue du droit des religions est mise à disposition selon les termes de la Creative Commons Attribution - Pas d'Utilisation Commerciale 4.0 International - CC BY-NC 4.0. 


\title{
Francis MESSNER (dir.), L'affiliation religieuse en Europe
}

Strasbourg, Presses universitaires de Strasbourg, 2017

\author{
Philippe Ségur
}

\section{RÉFÉRENCE}

Francis MESSNER (dir.), L'affiliation religieuse en Europe, Strasbourg, Presses universitaires de Strasbourg, 2017 (Société, droit et religion), 212 p.

1 Cet excellent ouvrage collectif s'intéresse à un sujet que l'individualisme, la volatilité, voire le consumérisme contemporain ne permettent plus de saisir sous l'angle traditionnel de l'osmose nationale, vectrice d'identité, entre un peuple et une religion. Jean-Paul Willaime remarque d'emblée que l'affiliation religieuse comme « lien qui unit un individu à un groupe ou à une organisation » remplace désormais l'appartenance religieuse. Cette évolution lexicale traduit le phénomène de mobilité spirituelle qui privilégie le rapport dynamique et provisoire d'affiliation/désaffiliation plutôt que celui, statique et durable, d'appartenance, mais aussi le déni par lequel certaines personnes et certains peuples se veulent désormais «sans filiation » et refusent leur héritage culturel religieux. Revenant sur ce thème, Brigitte Basdevant-Gaudemet retrace l'évolution historique qui passe d'une appartenance religieuse définie par une communauté territoriale à une appartenance religieuse nationale définie par l'État, lequel admet progressivement le pluralisme des affiliations jusqu'à ne plus s'identifier lui-même à une religion donnée. Ce dernier point, qui est décisif pour la dissociation entre identité nationale et appartenance religieuse, ouvre l'ère moderne de «l'affiliation». Dans une contribution très approfondie, Céline Ruet examine dans quelle mesure la Cour européenne des droits de l'homme protège le droit de s'affilier et de se désaffilier d'une religion ainsi que celui d'exprimer son affiliation (ce que garantit tant l'art. 9 CEDH que son art. 8 sous l'angle de l'expression de la personnalité). La traditionnelle recherche d'équilibre et de proportionnalité de la Cour de Strasbourg 
conjugue ici la liberté de religion avec les exigences nationales d'aménagement et d'usage de l'espace public tandis que l'évolution jurisprudentielle récente attire « dans l'orbite de l'article 9 les restrictions à la liberté religieuse liées aux obligations professionnelles ».

Dans un saisissant contrepoint, Françoise Curtit relève que la Cour de justice de l'Union européenne s'attache davantage au "noyau dur» de la croyance subjective de l'individu qu'aux liens institutionnels d'affiliation à une communauté de conviction ce qui sans être identique, n'est pas tout à fait étranger à la notion "d'identité vécue " qu'a pu forger la Cour européenne en d'autres circonstances. En outre, le droit de l'Union consacre plusieurs dérogations importantes qui intéressent la mention de l'affiliation religieuse: dérogation au principe de non-discrimination professionnelle sur le fondement de l'éthique religieuse de l'employeur, dérogation aux règles relatives à certains fichiers et traitements de données à caractère personnel quand la mention de l'affiliation religieuse y est nécessaire et légitime. On sera particulièrement intéressé par les implications inattendues d'un " droit à l'oubli », souvent mal compris et associé au droit à la rectification des données, lorsque les velléités de désaffiliation religieuse vont jusqu'à exiger l'effacement d'événements historiques comme le baptême. Après être revenu sur le débat relatif à la circoncision, Pierre-Henri Prélot met, de son côté, l'accent sur des problématiques peu connues de l'affiliation telles que la vérification de celle-ci par une autorité publique en matière d'absentéisme au travail, de dispense d'examens ou de permis d'inhumer dans les carrés réservés ou telles encore que la prohibition des statistiques ou l'existence d'un hypothétique «droit individuel à l'affiliation » : autant de réflexions ouvertes sur un droit que travaille de plus en plus le phénomène religieux.

Cette approche juridique originale de la manière dont l'individu adhère à une religion ou s'en sépare se poursuit avec de riches développements consacrés au droit italien (M. Ventura) et belge (R. Torfs), au droit des pays musulmans (M. Mouaqit), puis aux droits religieux eux-mêmes: droit hébraïque (F. Alvarez-Pereyre), droit canonique (P. Valdrini) et droit ecclésial protestant (J.-P. Willaime). On appréciera enfin l'apport tout en nuance de la dernière étude relative à une sociologie de l'affiliation au culte musulman (F. Frégosi). À ce riche tour d'horizon, il ne manque peut-être qu'une étude juridique détaillée du refus de l'apostasie en islam. Cette question n'est, en effet, abordée que passim alors que celles de l'excommunication et de la débaptisation qui, dans l'Église catholique, ne contreviennent pas au régime général des libertés sont explorées à plusieurs reprises dans l'ouvrage.

\section{AUTEURS}

\section{PHILIPPE SÉGUR}

Professeur de droit public, Université de Perpignan Via Domitia, Centre du droit économique et du développement (CDED) 